\title{
Role of Non Androgenic Factors in Hair loss and Hair Regrowth
}

\section{Rajendrasingh J Rajput ${ }^{*}$}

Hair Transplant Surgeon, 201 A Wing, Gasper Enclave, Ambedkar Road, Bandra West, Mumbai, India

*Corresponding author: Rajendrasingh J Rajput, Hair Transplant Surgeon, 201 A Wing, Gasper Enclave, Ambedkar Road, Bandra west, Mumbai, India, Tel: +91-2226415298; E-mail: drrajeshrajput@gmail.com

Received date: March 24, 2017; Accepted date: April 05, 2017; Published date: April 08, 2017

Copyright: () 2017 Rajput RJ. This is an open-access article distributed under the terms of the Creative Commons Attribution License, which permits unrestricted use, distribution, and reproduction in any medium, provided the original author and source are credited.

\begin{abstract}
Multiple nutritional, environmental and lifestyle factors can directly affect hair follicles or weaken and make them sensitive to the action of androgens. Patients having hair fall, thinning and poor growth can be in early stages of androgenetic alopecia. Hair loss can be corrected and hair growth can be improved by addressing these nonandrogenic factors. Recent research has shown that androgens inhibit hair growth through release of Transforming Growth Factor (TGF) $\beta 1$. Further study of this mechanism reveals that generation of Reactive Oxygen Species (ROS) induced by androgens leads to release of TGF $\beta 1$, explaining benefit of antioxidants in hair growth. The binding of ROS also causes hair loss by altering the cellular proteins and converting them to new antigens targeted by inflammatory and immune systems. Calorie restriction and individual micronutrient deficiencies lead to a new process of intracellular destruction or autophagy before cell apoptosis, which could explain cessation of hair growth. Telogen is not a resting phase but now defined as active conservation of follicles under unfavourable conditions. Thus any stress, trauma, metabolic change or insult causes telogen. Micronutrients zinc, copper, selenium maintain immunity, control inflammation and preserve antioxidant activity of the cells. Vitamins A, C, D have a role in phagocytosis and antibodies maintaining resistance. Vitamin D3 modulates the hair-inductive capacity of dermal papilla cells. Vitamin and micronutrient deficiencies are prevalent among all the population of the world. Some nutritional supplementation is necessary to achieve day to day requirements. Nutritive value of the foods has reduced over the years by $30 \%$. Endocrine Disrupting chemicals are creating further damage to the hormonal balance of the body. All these can be countered by a well-planned nutritional program which will also ensure strengthening and regrowth of hair follicles without the use of Finasteride.
\end{abstract}

Keywords: Androgens; Telogen; Finasteride; Apoptosis; Autophagy

\section{Introduction}

Clinically patients are seen presenting with varying degrees of hair fall, thinning, poor hair growth, loss of hair volume, change in texture, lack of shine, lack of bounce, limp hair which cannot be styled and remains flat. These conditions do not match the defined features of AGA, MPHL, FPHL or DUPA. All these complaints can be subclinical variations, partial presentations or precursors of any of the scientifically defined hair loss patterns [1]. The final clinical presentation depends on the severity of insult, extent of compromise and effective counter defence of the host. Prolonged, continued sever hair fall could precede development of AGA, or any of the defined hair loss conditions [1].

Hair loss can be due to androgens, genetics, micro inflammation, disruption or deregulation of hair growth cycles. Apart from androgens many more factors affect hair growth. Stress, pollution, nutrition, lifestyle, prolonged illness, medications, metabolic disease, smoking, alcohol, which disrupt or deregulate the hair growth cycles, have been associated with hair loss, thinning and poor growth. These factors affect the hair growth directly and also make the hair roots more sensitive and susceptible to the action of androgens.

\section{Understanding the Different Non Androgenic Mechanisms of Hair Loss}

\section{Role of oxidative stress in hair loss}

Lipid peroxidation, glutathione derivatives and nitric oxide are indicators of cellular destruction by ROS through oxidation. All these markers have been identified to be significantly raised in hair loss patients, providing evidence of the role of ROS in the mechanism of hair loss [2-5]. Inui, Fukuzato and Itami established that androgens inhibit hair growth through secretion of TGF $\beta 1$ [6-8]. Hee, et al. analysed details of this mechanism showing that androgens rise levels of ROS in the dermal papilla cells which in turn leads to secretion of TGF $\beta 1$ that inhibits hair growth. The experiment further demonstrated that, use of ROS scavengers blocked the release of TGF $\beta 1$ and reversed the inhibition of hair growth $[9,10]$. The evidence suggests that antioxidants can promote hair growth without the direct use of anti-androgens and utilizing anti androgens alone may not achieve complete clinical response in all patients of hair loss. Kalkan et al. proposed that the ROS forms covalent bond with endogenous proteins in the cells, producing structural changes in the proteins, leading to changing in their immune signature. The normal proteins are now recognised as new antigens, making them targets of immunity, inflammation and autoimmune reactions. The study indicates the importance of ROS scavengers and provides a rationale, for benefit from the use of antioxidants in hair loss management and alopecia areata [11]. 


\section{Apoptosis and autophagy triggered by lack of calories, poor nutrition and mineral deficiencies}

Studies by Kubibidila, Yu and the research by Fraker and King showed altered immune response in protein calorie malnutrition and individual nutrient deficiencies [12,13]. Trueb recognised these mechanisms in androgenetic alopecia [14] where nutritional deficiencies could lead to apoptosis of hair follicle cells [1]. Guimaraes, Yoshimori and Freker described a newly defined process of internal cell destruction through autophagy before proceeding to programmed cell death and apoptosis [15-17].

Autophagy has been recognised to play a role for providing nutrients during metabolic stress, nutritional deficiencies and starvation like conditions. Autophagy is a process of regulated destruction of intracellular proteins and organelles by partial selfdestruction to tide over amino acid, mineral and nutritional deficiencies. It is an attempt to prevent apoptosis. Autophagy arrests the progress of cellular metabolism, new cell division and growth When applied to hair cycles, autophagy explains the mechanism leading to telogen effluvium after illness, high fever, surgical trauma, states of interrupted or poor nutrition etc. Autophagy is the mechanism by which body maintains normal blood levels of nutrients by arresting and discontinuing hair growth. Clinically the nutrient levels may not show frank deficiencies as they are compensated and maintained by arresting hair growth. Body is in a state of compensated failure. As soon as we provide stimulation and restore nutrition the hair regrowth begins. The evidence supports correction of nutritional deficiencies to prevent hair loss and promote hair growth [15-17]. Goette and Odum in 1976, reported alopecia in crash dieters which may be due to the role of mechanisms like autophagy and uncorrected nutritional balance [18]. Yoshinori Oshumi of Japan has been granted the 2016 Nobel Prize in Medicine for his research on Autophagy. Freker [17] points out that zinc deficiency induces secretion of glucocorticoids leading to programmed cell death by initiating apoptosis. The effect is first seen in lymphocytes, T cells, B cells, thymus, liver, kidney, testes, it compromises host defence increases inflammation and propagates damage to other cell systems. Fibroblasts exhibit DNA breakage [18]. Zinc deficiency is a well-documented cause for hair loss $[19,20]$. The scientific facts suggest that providing adequate nutrients and avoiding deficiency states can play a role in preventing hair loss and achieving new hair growth.

\section{Telogen recognized as a stage of active conservation of the hair follicles}

Geyfman et al. have studied hair follicles in telogen. The new understanding has redefined Telogen not as a resting phase but a highly energy-efficient state of retaining hair follicles when conditions are unfavourable. These follicles are spared from destruction to launch a new hair regeneration cycle later, when conditions are more favourable. Regenerative responses of telogen hair follicles change as a function of time and can be divided into two sub-stages: early 'refractory' stage and the late 'competent' stage of telogen [21]. Clinically we see this telogen response after high fever, trauma, physical or emotional stress, crash dieting and a number of other factors that trigger telogen effluvium.

\section{Role of Microinflammation and Immunity}

The genetic analysis of male pattern baldness and the 5 alpha reductase genes by Ellis [22], histopathological and histochemical correlation of male pattern alopecia by Lattanand [23], revelation of inflammatory infiltrates and pathogenesis by Jaworsky [24] and analysis of cutaneous immunopathology in male pattern baldness by Young [25]. All have lead to Androgenetic Alopecia being recognized as a condition of altered hair growth due to lack of regulation of the natural cycles or premature aging of the hair follicle, affected by multiple factors.

Skin keratinocytes respond to antigens or trigger inflammation in response to repeated, exposure to pollution, UV damage, reactive oxygen species [26], nitric oxide [27], prostaglandins and histamine [28] leading to progressive inflammation. As mentioned earlier, Kalkan, Seçkin et al. [11], proposed that the ROS forms covalent bond with endogenous proteins in the cells, changing their immune signature and making them behave as new antigens, becoming targets of immunity, inflammation and autoimmune reactions. All these processes, lead to accumulation and release of intracellular cytokines. IL-1alpha, IL-1beta, which are shown to inhibit hair elongation in hair follicle cultures in vitro $[29,30]$. The same effect is also supported by cytokines and chemokine, monocyte chemo attractant protein-1 (MCP-1), [31], which has been identified to be active in hair follicles and sebaceous glands in androgenetic alopecia. Surrounding fibroblasts too can respond to these pro inflammatory stimuli [32]. Fabio Rinaldi studied the levels of pollutants in the air and their effect on the scalp, leading to hair loss, poor growth and a clinical condition of sensitive scalp syndrome [33]. Our previous published review also analyses hair loss due to pollution [34]. All the research encourages use of antioxidants, vitamins and minerals which can prevent altered immune response, to prevent hair loss and promote hair growth.

\section{Role of Vitamins and Minerals in Immunity and Inflammation}

Eugenio Mocchegiani has shown that micronutrients zinc, copper, selenium maintain immunity, control inflammation and preserve antioxidant activity of the cells $[35,36]$. Thurnham studied the interactions of micronutrients with other nutrients in the diet, nonnutrients, prescribed medicines, and lifestyle factors like smoking, tea and alcohol etc. [37], which can cause hair loss. Ströhle, Wolters and Hahn studied micronutrients as essential structural elements of antioxidant system, enzymes cofactors, components of transcription factors, and epigenetic modulators. They reported the influence of Vitamin C and Vitamin D on immunity, $\mathrm{T}$ cells phagocytosis, formation of antibodies, autoimmune response and resistance to infection [38,39]. Reichrath, Lehmann, et al. have regarded Vitamin A and Vitamin D as hormones due to the role in epithelial integrity and immunity [40]. Aoi, et al. have demonstrated that Vitamin D3 modulates the hair-inductive capacity of dermal papilla cells [41]. Thus making Vitamin D an important inclusion for promotion of hair growth. Beoy, et al. studied the benefit of $100 \mathrm{mg}$ mixed tocotrienol and alpha tocopherol resulting into $34 \%$ improvement in hair counts attributed to potent inhibition of lipid peroxidaiton and reduction of oxidative stress [42]. Jin, Zhu and Wu compared zinc, copper, iron and manganese contents in hair in patients with male pattern alopecia and healthy men confirming low levels of nutrients in patterned hair loss [43]. A recent study by Ozturk et al. compared BMI and levels of zinc, copper in hair, serum and urine of Turkish male patients with androgenetic alopecia, again confirming low levels in patients with androgenetic alopecia [20]. Ozturk pointed out that Zinc and Copper are required for enzymatic functions of Carbonic anhydrase, Superoxide dismutase, Polymerase, Collagenase, Cell division, Nucleic 
acid metabolism and several coenzymes. Zinc and Copper have antioxidant activity. Zinc stabilizes cell membrane prevents oxidative destruction by free radicals [20]. Skalnaya et al. showed a lower copper and zinc content in the hair of frontal area in comparison to the occipital area in women with AGA [44].

Harrison and Bergfeld mentioned the role of calorie restriction, fatty acids, crash dieting, starvation, zinc and iron deficiency in diffuse hair loss [45]. Betsy, Binitha and Sarita have directed attention to association between zinc, copper, selenium deficiencies and altered thyroid function leading to hair loss [46]. Rojas and Gosch studied zinc, iron, copper, selenium deficiencies as cause for hair loss following Bariatric Surgery and found that patients having lower hair loss had lower compromise of nutrients [47]. All these studies emphasise the role of micronutrients, vitamins, minerals in hair loss management.

\section{Nutrition Correction in Hair Loss Management Gaining Attention}

A Randomized, Double-Blind, Placebo-Controlled Study by Ablon G using shark cartilage and omega 3 showed decreased hair shedding in women [48]. Another randomized trial by Le Floc'h C, et al confirmed benefit with omega 3 and omega 6 in female pattern hair loss [49]. Simopoulos has presented a detail account of the benefits of omega 3 in inflammation and auto immune conditions [50].

There is rising interest in addressing hair loss with nutritional support leading to studies showing effective use of vitamin B6, calcium pentothenate, 1-cystine, 1-lysine and combination to treat hair loss and improve hair growth [51-55]. There are double blind placebo controlled trials showing benefit of nutritional supplements [56-62].

Dwyer 1994 indicated the role of subclinical dietary deficiencies in non-scarring hair loss [63]. Dietary deficiencies are common in population. Calorie restriction is a day to day practice becoming a way of life [64-66].

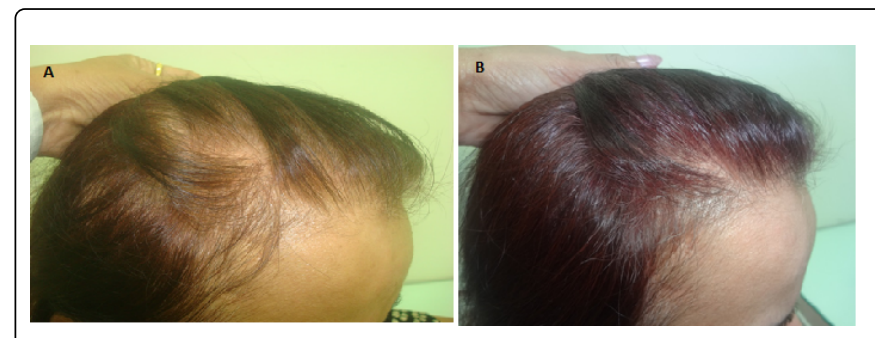

Figure 1A-1B: Thinning and poor hair growth in female patient; B: Improved hair quality and regrowth with nutritional correction and peptide cream, no minoxidil, no anti androgens.

\section{Nutritional Deficiencies are More Common than we can Perceive}

Vegetarianism and lacto vegetarian diet leads to defined nutritional deficiencies. Rauma and Mykkänen, reported low antioxidant levels in vegetarian diet due to lack of zinc and selenium [67]. Dietetic association position statement considers vegetarian diets can be low in protein, omega 3 fatty acids, iron, zinc, iodine, calcium, and vitamins $\mathrm{D}$ and $\mathrm{B}-12$, but these deficiencies can be carefully avoided [68]. Lacto vegetarian diets can lead to energy, protein, iron, calcium, zinc, betacarotene, and vitamin C deficiency [69].
People today satisfy their hunger with selection of wrong foods leaving an un quenched nutritional deficit which research workers have termed as the 'hidden hunger' [70]. Foods with good nutritional value are affordable only to high income groups. These are termed as income elastic protective foods [71-74].

Malnutrition is so common in adult and adolescent population around the world that an Adult Micronutrient Quality Index (AMQI) has been developed to study malnutrition in adults $[75,76]$.

Chicken are fattened faster using hormones, antibiotics, oral contraceptives, tranquilizers which pass on to consumers creating hormonal imbalance and risk of disease [77].

Endocrine disrupting chemicals are contaminating food through processing and packing technology. These mimic the action of hormones and cause imbalance leading to disease conditions [78]. Such altered metabolism could cause hair loss.

\section{Gradual Loss of Nutritive Value of Foods due to Soil Depletion and Farming Methods}

The nutritive value of foods itself has reduced over the years. Various studies show more than $30 \%$ reduction in nutritional content of foods when compared over the past 50 years. Anne-Marie Mayer reported significant reductions in the levels of $\mathrm{Ca}, \mathrm{Mg}, \mathrm{Cu}$ and $\mathrm{Na}$, in vegetables and $\mathrm{Mg}, \mathrm{Fe}, \mathrm{Cu}$ and $\mathrm{K}$ in fruits. The greatest change was the reduction of copper levels [79]. David Thomas has reported individual loss of nutrients in vegetables, fruits, milk and meat [80]. Davis Donald has compared the vitamin content showing loss of riboflavin and ascorbic acid over the past 50 years [81]. More data on reduced nutritive value of foods has been recently added by White and Broadley [82]. The author has published his own clinical experience with the use of low dose nutritional correction in hair loss management with a two year follow up showing consistent improvements in men and women [83] (Figures 1A,1B and 2A,2B).

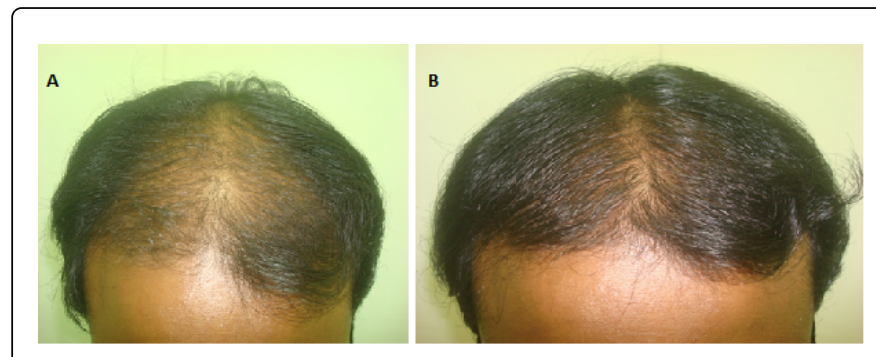

Figure 2A-2B: Frontal thinning and poor hair growth in male patient; B: Improved frontal hair quality and regrowth with nutritional correction and peptide cream, no minoxidil, no anti androgens.

\section{Conclusion}

Maintaining good nutritional balance of vitamins, micro nutrients, antioxidants can neutralize ROS, maintain immunity, phagocytosis, induce cell growth, counter effects of endocrine disrupting chemicals, prevent autophagy, apoptosis, derangement of body functions due to poor diet and loss of nutritional value of foods. Correction of these associated mechanisms must be included in our approach to successful hair loss management. Anti-androgens may not be the only basis of hair loss management. 


\section{References}

1. Trüeb RM, Tobin DJ, editors. Aging Hair. Berlin, Heidelberg: SpringerVerlag; 2010.

2. Girat M, Cervello I, Nogues MR, Puerto AM, Ortin F, et al. (1996) Glutathione, glutathione S-transferase and reactive oxygen species of human scalp sebaceous glands in male pattern baldness. J Invest Dermatol 107: 154-158.

3. Naziroglu M, Kokcam I (2000) Antioxidants and lipid peroxidation status in the blood of patients with alopecia. Cell Biochem Funct 18: 169-173.

4. Akar A, Arca E, Erbil H, Akay C, Sayal A, et al. (2002) Antioxidant enzymes and lipid peroxidation in the scalp of patients with alopecia areata. J Dermatol Sci 29: 85-90.

5. Koca R, Armutcu F, Altinyazar H, Gurel A (2005) Evaluation of lipid peroxidation, oxidant/antioxidant status and serum nitric oxide levels in alopecia areata. Medical Science Monitor 11: 296-299.

6. Inui S, Fukuzato Y, Nakajima T, Yoshikawa K, Itami S (2002) Androgeninducible TGF-beta1 from balding dermal papilla cells inhibits epithelial cell growth: a clue to understand paradoxical effects of androgen on human hair growth. FASEB J 16: 1967-1969.

7. Inui S, Fukuzato Y, Nakajima T, Yoshikawa K, Itami S (2003) Identification of androgen-inducible TGF-betal derived from dermal papilla cells as a key mediator in androgenetic alopecia. J Investig Dermatol Symp Proc 8: 69-71.

8. Itami S (2004) Pathomechanism of androgenetic alopecia and new treatment. Japanese Journal of Geriatrics 41: 598-600.

9. Hee CE (2008) The involvement of ROS on androgen inducible TGF beta 1 regulation derived from dermal papilla cells; a suggestive implication of ROS on androgenetic alopecia. Journal of the American Academy of Dermatology 58: AB84.

10. Shin H, Yoo HG, Inui S, Itami S, Kim IG, et al. (2013) Induction of transforming growth factor-beta 1 by androgen is mediated by reactive oxygen species in hair follicle dermal papilla cells. BMB Rep 46: 460-464.

11. Kalkan G, Seçkin HY, Benli I, Akbaş A, Baș Y, et al. (2015) Relationship between manganese superoxide dismutase (MnSODAla-9Val) and glutathione peroxidase (GPx1 Pro $197 \mathrm{Leu}$ ) gene polymorphisms and alopecia areata. Int J Clin Exp Med 8: 21533-21540.

12. Kubibidila S, Yu L, Ode D, Warrier RP (1993) The immune response in protein-energy malnutrition and single nutrient deficiencies. In: Human Nutrition: A Comprehensive Treatise 8: 121-157.

13. Fraker P, King LE (2004) Reprogramming of the immune system during zinc deficiency. Ann Rev Nutr 24: 277-298.

14. Trüeb RM (2002) Molecular mechanisms of androgenetic alopecia. Exp Gerontol 37: 981-990.

15. Guimaraes C, Linden R (2004) Programmed cell death, apoptosis and alternate death styles. Eur J Biochem 271:1638-1650.

16. Yoshimori T (2004) Autophagy: A regulated bulk degradation process inside cells Biochem Biophys Res Commun 313: 453-458.

17. Fraker Pamela J (2005) Roles for Cell Death in Zinc Deficiency. J Nutr 135: 359-362.

18. Goette DK, Odum RB (1976) Alopecia in crash dieters. JAMA 235: 2622-2623.

19. Betsy A, Binitha M, Sarita S (2013) Zinc Deficiency Associated with Hypothyroidism: An Overlooked Cause of Severe Alopecia. Int J Trichology 5: 40-42.

20. Ozturk P, Kurutas E, Ataseven A, Dokur N, Gumusalan Y, et al. (2014) BMI and levels of zinc, copper in hair, serum and urine of Turkish male patients with androgenetic alopecia. J Trace Elem Med Biol 28: 266-270.

21. Geyfman M, Plikus MV, Treffeisen E, Andersen B, Paus R (2015) Resting no more: re-defining telogen, the maintenance stage of the hair growth cycle. Biol Rev Camb Philos Soc 90: 1179-1196.

22. Ellis JA, Stebbing M, Harrap SB (1998) Genetic Analysis of male pattern baldness and the 5 alpha reductase genes. J Invest Dermatol 110: 849-853.

23. Lattanand A, Johnson WC (1975) Male pattern alopecia a histopathological and histochemical study. J Cutan Pathol 2: 58-70.
24. Jaworsky C, Klingman AM, Murphy GF (1992) Characterisation of inflammatory infiltrates in male pattern alopecia: implication of pathogenesis. Br J Dermatol 127: 239-246.

25. Young JW, Conte ET, Leavitt ML, Nafz MA, Schroeter AL (1991) Cutaneous immunopathology of androgenetic alopecia. J Am Osteopath Assoc 91: 765-771.

26. Trenam CW, Blake DR, Morris CJ (1992) Skin Inflammation: reactive oxygen species and the role of iron. J Invest Dermatol 99: 675-682.

27. Ialenti A, Inaro A, Moncada S, DiRosa M (1992) Modulation of acute inflammation by endogenous nitric oxide. Eur J Pharmacol 211:177-182.

28. Hruza LL, Pentlan AP (1993) Mechanisms of UV-induced inflammation. J Invest Dermatol 100: 35-41.

29. Hermon CS, Nevins TD (1993) IL-1alpha inhibits human hair follicle growth and hair fiber production in whole-organ culture. Lymphokine Cytokine Res 12: 197-202.

30. Mahe YF, Buan B, Billoni N, Loussouarn G, Michelet JF, et al. (1996) Proinflammatory cytokines cascade in human plucked hair. Skin Pharmacol 9: 366-375.

31. Mahé YF, Michelet JF, Billoni N, Jarrousse F, Buan B, et al. (2000) Androgenetic Alopecia and microinflammation. Int J Dermatol 39: 576-584.

32. Smith RS, Smith TJ, Bleden TM, Phipps RP (1997) Fibroblasts as sentinel cells. Synthesis of chemokines and regulation of inflammation. Am J Pathol 151: 317-322.

33. Rinaldi F (2008) Pollution, scalp and hair transplant. Hair Transplant Forum Int 18: 227.

34. Rajput R (2015) Understanding Hair Loss due to Air Pollution and the Approach to Management. Hair Ther Transplant 5: 133.

35. Eugenio M, Laura C, Robertina G, Francesco P, Andrea B, et al. (2012) Micronutrient ( $\mathrm{Zn}, \mathrm{Cu}, \mathrm{Fe})$-gene interactions in ageing and inflammatory age-related diseases: Implications for treatments. Ageing Research Reviews 11: 297-319.

36. Mocchegiani E, Costarelli L, Giacconi R, Malavolta M, Basso A, et al. (2014) Micronutrient-gene interactions related to inflammatory/immune response and antioxidant activity in ageing and inflammation. A systematic review. Mech Ageing Dev 137: 29-49.

37. Thurnham DI (2004) An overview of interactions between micronutrients and of micronutrients with drugs, genes and immune mechanisms. Nutr Res Rev 17: 211-40.

38. Ströhle A, Wolters M, Hahn A (2011) Micronutrients at the interface between inflammation and infection--ascorbic acid and calciferol: part 1, general overview with a focus on ascorbic acid. Inflamm Allergy Drug Targets 10: 54-63.

39. Ströhle A, Wolters M, Hahn A (2011) Micronutrients at the interface between inflammation and infection--ascorbic acid and calciferol. Part 2: calciferol and the significance of nutrient supplements. Inflamm Allergy Drug Targets 10: 64-74.

40. Reichrath J, Lehmann B, Carlberg C, Varani J, Zouboulis CC, et al. (2007) Vitamins as hormones. Horm Metab Res 39: 71-84.

41. Aoi N, Inoue K, Chikanishi T, Fujiki R, Yamamoto H, et al. (2012) 1a, 25dihydroxyvitamin D3 modulates the hair-inductive capacity of dermal papilla cells: therapeutic potential for hair regeneration. Stem Cells Transl Med 1: 615-626.

42. Beoy LA, Woei WJ, Hay YK (2010) Effects of Tocotrienol Supplementation on Hair Growth in Human Volunteers. Trop Life Sci Res 21: 91-99.

43. Jin W, Zhu Z, Wu S, Zhang X, Zhou X (1998) Determination of zinc, copper, iron and manganese contents in hair for MPA patients and healthy men. Guang Pu Xue Yu Guang Pu Fen Xi 18:91-93.

44. Skalnaya MG, Tkachev VP (2011) Trace elements content and hormonal profiles in women with androgenetic alopecia. J Trace Elem Med Biol 25: 50-53.

45. S Harrison, W Bergfeld (2009) Diffuse hair loss: Its triggers and management. Cleve Clin J Med 76: 361-367. 
46. Rojas P, Gosch M, Basfi-Fer K, Carrasco F, Codoceo J, et al. (2011) Alopecia in women with severe and morbid obesity who undergo bariatric surgery. Nutr Hosp 26: 856-862.

47. Ablon G (2015) A 3-Month, Randomized, Double-Blind, PlaceboControlled Study Evaluating the Ability of an Extra-Strength Marine Protein Supplement to Promote Hair Growth and Decrease Shedding in Women with Self-Perceived Thinning Hair. Dermatol Res Pract 2015: $1-18$.

48. Le Floc'h C, Cheniti A, Connétable S, Piccardi N, Vincenzi C, et al. (2015) Effect of a nutritional supplement on hair loss in women. J Cosmet Dermatol 14: 76-82.

49. Simopoulos AP (2002) Omega-3 fatty acids in inflammation and autoimmune diseases. J Am Coll Nutr 21: 495-505.

50. Budde J, Tronnier H, Rahlfs VW, Frei-Kleiner S (1993) Systemic therapy of diffuse effluvium and hair structure damage. Hautarzt 44: 380-384

51. Ahrens J (1994) Systemic treatment of diffuse hair loss. Therapiewoche Schweiz 10: 551-554.

52. Gehring W, Gloor M (2000) The phototrichogram as a method for assessing hair care preparations the example of a combination of millet, fruit extract, L-cystine and calcium pantothenate. Z Hautkr 75: 419-423.

53. Brzezińska-Wcisło L (2001) Evaluation of vitamin B6 and calcium pantothenate effectiveness on hair growth from clinical and trichographic aspects for treatment of diffuse alopecia in women. Wiad Lek 54: 11-18.

54. Addor FAS, Bombarda PCP, Bombarda Júnior MS, Abreu FF (2014) Influence of nutritional supplementation in the treatment of telogen effluvium: clinical assessment and digital phototrichogram in 60 patients. Surg Cosmet Dermatol 6: 131-136.

55. Petri H, Perchalla P, Tronnier H (1990) Effective medical treatment for hair structure damage and diffuse Effluvien - a comparative double-blind study. Schweiz Rundsch Med Prax 79: 1457-1462.

56. Thom E (2001) Efficacy and tolerability of Hairgain in individuals with hair loss: a placebo-controlled, double-blind study. J Int Med Res 29: 2-6.

57. Lengg N, Heidecker B, Seifet B, Trüeb RM (2007) Dietary supplement increases anagen hair rate in women with telogen effluvium: Results from a double blind placebo controlled trail. Therapy 4: 59-65.

58. Jacquet A1, Coolen V, Vandermander J (2007) Effect of dietary supplementation with INVERSION femme on slimming, hair loss, and skin and nail parameters in women. Adv Ther 24: 1154-1171.

59. Glynis Ablon (2012) A Double-blind, Placebo-controlled Study Evaluating the Efficacy of an Oral Supplement in Women with Selfperceived Thinning Hair. J Clin Aesthet Dermatol 5: 28-34.

60. Beer C, Wood S, Veghte RH (2014) A Clinical Trial to Investigate the Effect of Cynatine HNS on Hair and Nail Parameters. Scientific World Journal 2014: 1- 6

61. Rizer RL, Stephens TJ, Herndon JH, Sperber BR, Murphy J, et al. (2015) A marine protein-based dietary supplement for subclinical hair thinning/ loss: Results of a multisite, double-blind, placebo-controlled clinical trial. Int J Trichol 7: 156-166.

62. Dwyer JT (1994) Vegetarian eating patterns: Science, values, and food choices - Where do we go from here? Am J Clin Nutr 59: 1255S1262S.

63. Misner B (2006) Food Alone May Not Provide Sufficient Micronutrients for Preventing Deficiency1. J Int Soc Sports Nutr 3: 51-55.

64. Calton JB (2010) Prevalence of micronutrient deficiency in popular diet plans J Int Soc Sports Nutr 7: 24.

65. Affenito SG, Thompson DR, Franko DL, Striegel-Moore RH, Daniels SR et al. (2007) Longitudinal assessment of micronutrient intake among
African-American and white girls: The National Heart, Lung, and Blood Institute Growth and Health Study. J Am Diet Assoc 107: 1113-1123.

66. Rauma AL, Mykkänen H (2000) Antioxidant status in vegetarians versus omnivores. Nutrition. 16: 111-119.

67. Craig WJ, Mangels AR, American Dietetic Association (2009) Position of the American Dietetic Association: vegetarian diets. J Am Diet Assoc 109: 1266-1282.

68. Tupe R, Chiplonkar SA (2010) Diet patterns of lactovegetarian adolescent girls: need for devising recipes with high zinc bioavailability. Nutrition 26: 390-398.

69. Indian National Science Academy (2009) Nutritional Security for IndiaIssues and Way Forward. A Position Paper.

70. Andreyeva T, Long MW, Brownell KD (2010) The Impact of Food Prices on Consumption: A Systematic Review of Research on the Price Elasticity of Demand for Food. Am J Public Health 100: 216-222.

71. Green R, Cornelsen L, Dangour AD, Turner R, Shankar B, et al. (2013) The effect of rising food prices on food consumption: systematic review with meta-regression. BMJ 346: f3703.

72. Stern D, Poti JM, Ng SW, Robinson WR, Gordon-Larsen P, et al. (2016) Where people shop is not associated with the nutrient quality of packaged foods for any racial-ethnic group in the United States. Am J Clin Nutr103: 1125-1134.

73. Lee AJ, Kane S, Ramsey R, Good E, Dick M (2016) Testing the price and affordability of healthy and current (unhealthy) diets and the potential impacts of policy change in Australia. BMC Public Health 16: 315.

74. Chiplonkar SA, Tupe R (2010) Development of a diet quality index with special reference to micronutrient adequacy for adolescent girls consuming a lacto-vegetarian diet. J Am Diet Assoc 110: 926-931.

75. Ponce X, Rodríguez-Ramírez S, Mundo-Rosas V, Shamah T, Barquera S, et al. (2014) Dietary quality indices vary with socio demographic variables and anthropometric status among Mexican adults: a crosssectional study. Results from the 2006 National Health and Nutrition Survey. Public Health Nutr 17: 1717-1728.

76. Renu G, Suzanne MS (2016) Breast Cancer and Environmental Risk Factors, New York State.

77. Schug TT, Janesick A, Blumberg B, Heindel JJ (2011) Endocrine Disrupting Chemicals and Disease Susceptibility. J Steroid Biochem Mol Biol 127: 204-215.

78. Mayer AM (1997) Historical changes in the mineral content of fruits and vegetables. British Food Journal 99: 207-211.

79. David Thomas (2003) A Study on the Mineral Depletion of the Foods Available to us as a Nation over the Period 1940 to 1991. Nutr Health 17: 85-115.

80. Davis DR, Epp MD, Riordan HD (2004) Changes in USDA food composition data for 43 garden crops, 1950 to 1999. J Am Coll Nutr 23: 669-682.

81. White PJ, Broadley MR (2005) Historical variation in the mineral composition of edible horticultural products. Journal of Horticultural Science and Biotechnology 80: 660-667.

82. Rajput R (2008) Cyclical Medicine for Hair loss Management and Improving Results in Hair transplantation. Hair Transplant Forum International 18: 208.

83. Rajput R (2010) Controversy: Is there a Role for Adjuvants in the Management of Male pattern hair loss? J Cutan Aesthet Surg 3: 82-86. 